\title{
Innovative Model of 3D Synergetic Management in Major Infrastructural Project
}

\author{
$\mathrm{Na} Z \mathrm{Zhao}^{1, \mathrm{a}}$ and Shi $\mathrm{An}^{1, \mathrm{~b}^{*}}$ \\ ${ }^{1}$ School of Management, Harbin Institute of Technology, 150001, China \\ azhaona@hit.edu.cn, banshi@hit.edu.cn
}

Keywords: Coordinated management; 3D Synergetic; Major constructions

\begin{abstract}
Objective: Rapid development of economic construction that requires modern major engineering must implement synergetic management model. Not only does it increase the operation efficiency in major engineering works, it can also lower the risk in the engineering works and raise the management ability of the engineering team. Methods: the thesis in to optimize the coordinated management by considering stereoscopic structure in major projects, and through it to build a 3D Synergetic model. Results: This article establishes the 3D synergetic management model from information dimension, phase dimension and linkage dimension, which will be beneficial to enrich the theoretical connotation of major construction management and will provide maximum guarantee to the success of the construction. Conclusion: by testing the 3D Synergetic Management in Major Infrastructural Project, the thesis comes up with a 3D Synergetic Management, which enriches the theories of major projects.
\end{abstract}

\section{Introduction}

Major engineering works in this article are large-scale investment by the government, which is large-scale construction project that has significant effect in the national economy and social development. Its scope includes large-scale infrastructural projects such as transportation, water conservation and urban construction. Since major engineering works have decisive influence and status in the social economy, management of major construction projects has always been one of the research focuses in management science [1]. In many studies of major engineering projects, the structure of synergetic management innovative model has a direct, deciding effect to the level of construction management.

\section{Literature Review}

Synergetic is proposed by a German professor, in the 70 s of the $20^{\text {th }}$ century. Synergetic utilizes a comprehensive approach to solve issues. It mainly coordinates by grasping the subject, key studying and discussing each part of the system in order to produce an overall effect. Major engineering works have a complicated system that has a high complexity, multiple subjects and high risks. If the works deviates from synergetic management, it will likely become chaotic [1].

Linkage Synergy

To achieve synergetic management in major constructions, scientific research, design, construction, material, machinery, technical information and other aspects are involved. It accords to synergy of multiple subjects as basis of innovative activity [2]. Effective cooperating relation between different departments is needed. Construction synergy is a combined process that gathers a large amount of resource factors. Cross-subjective coordination is the key factor in influencing building innovations [3]. Coordination between subjects is known as an effective way to increase efficiency and promote innovation. Integration ability of main project subject, close synergy and open communication are key factors in successful innovations [4].

Phase Synergy

Starting off from the whole system of major construction, some researchers proposed a concept of system thinking in engineering management [5]. By running through the management activities in the construction life cycle, the overall optimized target of construction life cycle was reached. 
Synergetic management based on phased discussion can simultaneously complete the function and the structure of major engineering works as well as coordinate each stage of life cycle in major engineering works [6]. That is to consider the plan, synergy, construction, management, operation, usage and maintenance of the engineering, which lets the different stages in major engineering works have corresponding evaluation [7]. Consequently, conflicts that may be produced in the developmental process of the construction are solved, repetition and alternation are lowered. This leads to a shortened time for the developmental process of the construction while the cost is reduced and the quality is enhanced [8].

Information Synergy

In the implementation process of a major construction, whether information is appointed by leaders or feedback is given by workers of the basic level, the delivery time of information transfer is very important [9]. That is because it relates to the management and controlling of construction cost and quality targets. The effective time period of information synergy is one of the significant points in implementing the construction [10]. Thus, there are scholars that consider the behavior of project participants from the aspect of earnings to proceed to synergy and induction. This type of effective idea can improve the organizational relationship in major engineering works and enhance the management performance. From the aspect of synergy optimization, establish a decision model of synergy in limitation period. Consider going through the measures of synergy optimization from looking at maximum revenue of the construction. Then, the synergetic management in information limitation period of major engineering works will be achieved.

\section{Basic Model}

On the account of the current studies of management engineering, analytical model of major construction 3D synergetic based on the view of synergetic is established. As shown in Fig. 1:

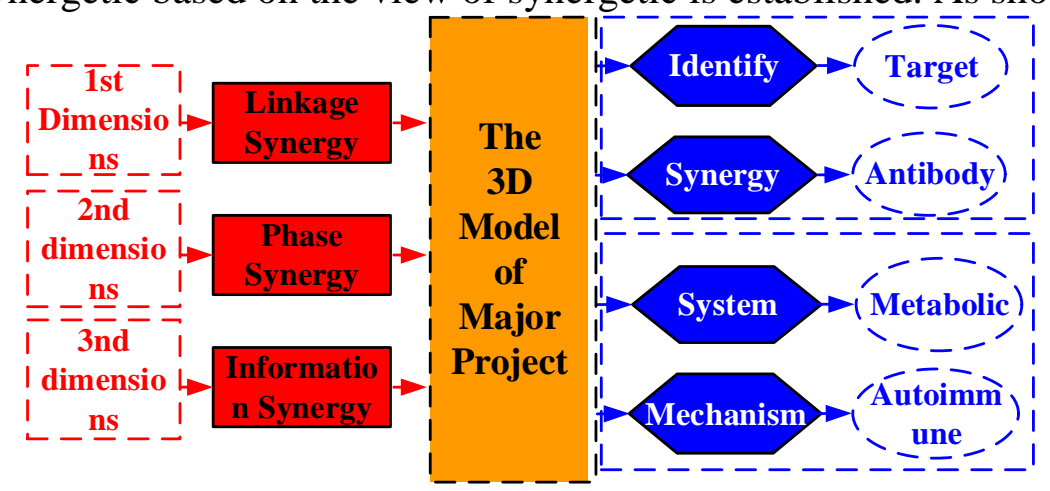

Figure 1. the innovative model of 3D synergetic management

The innovative model of 3D synergetic management with information, phase and linkage. If the three variable synergies cannot be achieved, the difference between project participants will increase in multiple times, which will lead to difficulty in coordinating information, organizational paralysis and fail linkage. Therefore, the 3D synergetic management model unifies, coordinates and optimizes each stage in major construction management and governs overall planning.

\section{Application of Model}

1). 3D synergetic management can promote the improvement of project performance. The major construction projects involve numerous related stakeholders and complicated organizational environment. In order to effectively externally and internally communicate and coordinate major engineering works, the management process has to manage matters and provide a standard procedure for the related stakeholders of the project. This helps to achieve common view for each subject in the engineering construction. Thus, the project performance is effectively improved in the management practice of major engineering works. 
2). 3D synergetic management can maximize evasion of project risk. Large-scale investment and long-term construction causes many uncertain risks in major construction projects. 3D synergetic management system can overall manage the each stage in the construction and in time monitor the changes of risks in the project. This can maximize evasion of project risk and increase the ability of the project to resist risks.

3). 3D synergetic management assists in training the ability of construction management and measures the maturity of the management, which leads to standardization, quantification and control in major construction works. 3D synergetic management means providing standard procedure to engineering management. Thus, standardized project management can train management team in the ability to manage and organize the project.

4). 3D synergetic management is an important guarantee in successful major construction, in which the success is difficult to control. The system thinking in 3D synergetic management can use the overall thinking to integrate every stage in the project and management activity as a whole. Therefore, it helps to increase the success of the project.

\section{Conclusion}

Generally speaking, this article centers major engineering works. The structure of 3D synergetic management model is a significant development in the theory of modern synergetic management. The structure of 3D synergetic management system in major construction can satisfy the requirements of general engineering management as well as adapting to special requirements, which reflects the combination of the construction and management theory. Engineering works of major infrastructure in China are frequently developed. In these significant constructions that concern the national economy and the people's livelihood, establishing perfect synergetic management system has important theoretical significance and practical significance in improving the engineering management level in China.

\section{Acknowledgement}

This work was supported by the National Natural Science China (Grant No. 71390522), China Postdoctoral Science Foundation and Hei Long Jiang Postdoctoral Foundation of China.

\section{References}

[1] Kumaraswamy M, Love P E D, and Dulaimi M. Integrating procurement and operational innovations for construction industry development $[\mathrm{J}]$. Engineering Construction \& Architectural Management, 2004, 11(5): 323-334.

[2] Rutten M E J, Dorée A G, and Halman J I M. Innovation and interorganizational cooperation: a synthesis of literature [J]. Construction Innovation, 2009, 9(3):285-297.

[3] Bresnen M and Marshall N. Partnering in construction: a critical review of issues, problems and dilemmas [J]. Construction Management and Economics 2000; 18(2):229-37.

[4] Geyer A and Davies A. Managing Project-System Interfaces: Case Studies of Railway Projects in Restructured UK and German Markets [J]. Research Policy, 2000, 29: 991-1013.

[5] Eliott R J, Shen J. Credit risk and contagion via self-exciting default Intensity. Annals of Finance, 2015: 1-26.

[6] Na Zhao, Shi An. Collaborative Management of Complex Major Construction Projects: AnyLogic-Based Simulation Modelling. Discrete Dynamics in Nature and Society, Volume 2016 (2016), http://dx.doi.org/10.1155/2016/6195673

[7] Wei Wan, Study of Competition and Cooperation in Engineering Project Risk Control and Management, Seventh International Conference on Dynamic Systems and Applications \& Fifth 
International Conference on Neural, Parallel and Scientific Computations. May 27-30, 2015. USA

[8] Almeida N M, Sousa V,Dias L A,et al. Engineering risk management in performance-based building environments. Journal of Civil Engineering \& Management,2015,21(2): 218-230.

[9] Marle, Franck; Vidal, Ludovic-Alexandre. (2014). Forming Risk Clusters in Projects to Improve Coordination between Risk Owners. Journal of Management in Engineering, 30(4), 06014001.

[10] Lavikka, RH; Smeds, R \& Jaatinen, M (2015). Coordinating collaboration in contractually different complex construction projects. Supply Chain Management-An International Journal, 20(2), 205-217. 